\title{
MITOCHONDRIAL-DNA ANALYSES AND THE ORIGIN AND RELATIVE AGE OF PARTHENOGENETIC LIZARDS (GENUS CNEMIDOPHORUS). III.

\author{
C. VELOX AND C. EXSANGUIS
}

\author{
Craig C. Moritz, ${ }^{1,3}$ John W. Wright, ${ }^{2}$ AND WesLey M. Brown ${ }^{1.4}$ \\ 'Laboratory of Molecular Systematics, Museum of Zoology, and Department of Biology, \\ University of Michigan, Ann Arbor, MI 48109-1079 \\ ${ }^{2}$ Section of Herpetology, Natural History Museum of Los Angeles County, \\ Los Angeles, CA 90007
}

\begin{abstract}
Mitochondrial DNAs (mtDNAs) of two unisexual, parthenogenetically reproducing species of whiptail lizards (Cnemidophorus velox and $C$. exsanguis) and their bisexual relatives were compared by restriction-enzyme analysis to assess levels of mtDNA variation and to establish the maternal ancestry of the unisexuals. No cleavage-site differences were found to be diagnostic between $C$. velox and $C$. exsanguis mtDNAs, suggesting an ancestry rooted in the same maternal lineage. The mtDNA of the unisexuals is relatively homogeneous, indicating that these lineages are of recent origin. Phylogenetic analysis revealed that the maternal ancestor of both $C$. velox and C. exsanguis was most probably $C$. burti stictogrammus, $C$. costatus barrancorum, or an unidentified taxon closely related to them. In addition, the mtDNA analyses demonstrate conclusively that the triploid species $C$. velox could not have been formed by the fertilization of an unreduced (diploid) C. inornatus egg, further strengthening the hypothesis that parthenogenesis in Cnemidophorus results from hybridization.
\end{abstract}

Received October 22, 1987. Accepted February 27, 1989

One-third of the approximately 50 species in the lizard genus Cnemidophorus are unisexual and consist exclusively of parthenogenetically reproducing females (see reviews by Cole [1975], Wright [1978], and Maslin and Secoy [1986]). In combination, studies of morphology, karyotypes, and allozymes have provided unequivocal evidence that these unisexual taxa originated via interspecific hybridization (see above reviews and Dessauer and Cole [1989] for discussion and references), which has led to the hypothesis that parthenogenesis in Cnemidophorus is a direct result of hybridization. However, hypotheses in which parthenogenesis preceeds hybridization have also been proposed (Cuellar, 1974; Darevsky et al., 1985). To test these hypotheses, it is necessary to identify with precision the bisexual taxa that gave rise to the unisexuals. Detailed hybrid genealogies have been established for $C$. neomexicanus and the $C$. tesselatus complex and for several sexlineatus-group uni-

\footnotetext{
${ }^{3}$ Present address: Department of Zoology, University of Queensland, St. Lucia, QLD 4067, Australia.

4 To whom reprint requests should be sent.
}

sexuals (discussed in Densmore et al. [1989a, $1989 \mathrm{~b}$ ). However, the precise ancestries for many other unisexual lineages in Cnemidophorus are unknown.

In this study, we analyzed mtDNA from the parthenogenetic species $C$. velox and $C$. exsanguis. Both are triploid, each with three chromosome complements typical of the sexlineatus group (Lowe et al., 1970). Good and Wright (1984) compared the allozymes of $C$. exsanguis with those of its putative bisexual relatives and concluded that a haploid complement of genes from each of three different species was present. Two of these were identified as coming from $C$. septemvittatus and $C$. inornatus, with the third coming from either $C$. costatus (specifically C. c. barrancorum) or C. burti stictogrammus. The situation for $C$. velox is somewhat different. Based on allozyme analyses, Neaves (1969) suggested that two of the haploid genomes in $C$. velox were from $C$. inornatus, but he was unable to identify the source of the third. The twofold contribution of $C$. inornatus was confirmed by Dessauer and Cole (1989), who in addition identified the third genome to be allozymically similar to that of $C$. burti. 


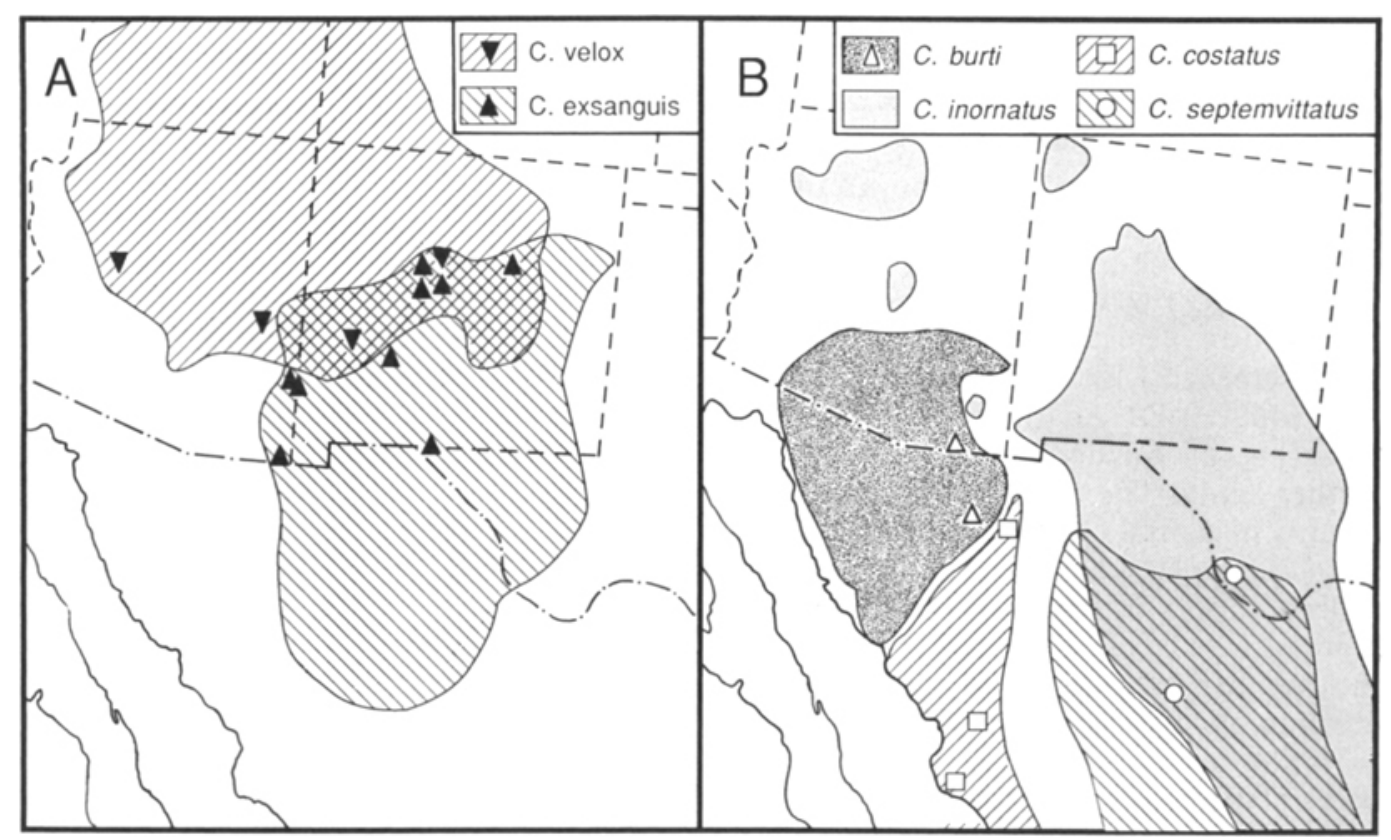

Fig. 1. Map of the southwestern United States and adjacent parts of Mexico showing portions of the geographic ranges and sampling points for six Cnemidophorus species. Sampling points for the Jefferson County, Oregon, $C$. velox and the Aguascalientes $C$. septemvittatus scalaris are not shown. More detailed locality data for $C$. inornatus and $C$. septemvittatus are given in Densmore et al. (1989b) and Densmore et al. (1989a), respectively.

Mitochondrial DNA (mtDNA) is especially useful for studying the ancestry and evolution of unisexual species (reviewed in Densmore et al. [1989b] and in Moritz et al. [1987, 1989]). Accordingly, restrictionendonuclease cleavage sites in mtDNA were compared within and between these two unisexuals and among related bisexual species in the sexlineatus group to determine 1) the extent of variation among the mtDNAs of the unisexuals and 2) their maternal ancestry. The mtDNA data also provided a means to test one aspect of the competing hypothesis about the origin of parthenogenesis.

\section{Materials AND Methods}

The mtDNAs were prepared from fieldcollected lizards (Fig. 1, Appendix) and analyzed as described in Densmore et al. (1985, $1989 \mathrm{~b}$ ). The sizes of the DNA fragments were determined by electrophoresis through agarose and polyacrylamide gels, using $M b o$ I-digested Hela cell mtDNA, Hae III-di- gested $\Phi$ X174 RF-DNA and Hind III-digested lambda-phage DNA as size standards.

Sequence divergence between mtDNAs was estimated from 1) cleavage-site changes inferred from the fragment patterns produced by endonucleases that cleave at 4-bp sites and 2) comparisons of cleavage maps, using the equations of Nei and Tajima (1983) in a program described by Nei et al. (1985). This program was also used to cluster the mtDNAs according to their sequence-divergence estimates by UPGMA (Sneath and Sokal, 1973). Analysis of character data (presence/absence of cleavage sites) using Wagner and Dollo parsimony criteria was accomplished with PAUP (version 2.4; available from D. L. Swofford, Illinois Natural History Survey, Champaign) and PHYLIP (version 2.9; available from J. Felsenstein, Department of Genetics, University of Washington, Seattle), respectively. The stability of the Wagner parsimony cladogram was evaluated by bootstrapping (Felsenstein, 1985) using PHYLIP. 


\section{RESULTS}

Variation Among C. velox and C. exsanguis $m t D N A s$

Emphasis was placed on analyzing mtDNAs that represented the geographic diversity of each species, rather than on examining large series of samples from any one locality. Thus, of the $37 \mathrm{mtDNAs}$ initially screened with $X b a$ I and $E c o R$ V, 20 individual mtDNAs drawn from 13 localities (Fig. 1, Appendix) were selected for further study. The $C$. velox from Jefferson County in central Oregon represent a recent introduction.

Two classes of variation were observed among these $20 \mathrm{mtDNAs}$ : 1) variation in the number or location of cleavage sites, attributable to base substitutions, and 2) variation in the lengths of fragments independent of alterations in the number of sites.

The observed cleavage-site variation ( $\mathrm{Ta}$ ble 1) may overestimate the actual number of substitutions, because several of the endonucleases employed have overlapping recognition sequences. Thus, the same base substitution may account for the changes in $B c I$ I (TGATCA) and $M b o$ I (GATC) in the VI $C$. velox mtDNA and for the alterations in $N c i$ I (CC[C/G]GG) and $M s p$ I (CCGG) in the E2 and E3 $C$. exsanguis samples, respectively (Table 1). When these correlated site changes are counted only once, the minimum number of substitutions among the cleavage sites assayed in these mtDNAs varies from one to four (Table 2). Estimates of percentage sequence divergence were derived from analyses of mtDNAs digested with three enzymes ( $M b o \mathrm{I}, R s a \mathrm{I}$, and $M s p$ I) that cleave at 4-bp sites. Given the very low level of sequence difference, it was possible to infer individual cleavage-site changes and to use these, rather than fragment comparisons, to estimate average sequence divergence (Brown, 1980). The divergence estimates obtained by this approach varied from zero to $0.7 \%$ (Table 2 ). The mean sequence divergence among the nine cleavage types distinguishable by $M b o \mathrm{I}, R s a \mathrm{I}$, and $M s p \mathrm{I}$ was $0.4 \%$, and the mean of all pairwise comparisons of $C$. velox and $C$. exsanguis mtDNAs was $0.22 \%$.

Three types of length variation were encountered among the $20 \mathrm{mtDNAs}$. In the first type, one of the fragments produced by a particular enzyme varied by small increments over a range of about $500 \mathrm{bp}$. For example, the largest fragment of the $M b o$ I digests varied from $3.35 \mathrm{~kb}$ to $3.87 \mathrm{~kb}$, the fourth largest fragment of $R s a$ I digests varied from $1.55 \mathrm{~kb}$ to $2.00 \mathrm{~kb}$, and the third largest fragment produced by Hinc II digests varied from $3.00 \mathrm{~kb}$ to $3.50 \mathrm{~kb}$. This length variation was strongly correlated among all enzymes except $M s p$ I, where multiple copies of a 64-bp fragment largely replaced the length variation. Also, seven of the 20 samples were obviously heteroplasmic with respect to these length-variable fragments. This variation parallels in detail the length variation reported among $C$. tesselatus mtDNAs (Densmore et al., 1985) and is likewise attributed to variation in the copy number of a 64-bp tandem repeat.

The second type of length variation involved a 65 -bp sequence that was present in most but not all of the $C$. exsanguis mtDNAs. This type of variation was detected in digests with Hinc II (1.03-kb fragment replaced by $1.10-\mathrm{kb}$ fragment), $M s p$ I (0.075-kb fragment replaced by $0.140-\mathrm{kb}$ fragment), and $M b o$ I ( $0.77-\mathrm{kb}$ fragment replaced by $0.84-\mathrm{kb}$ fragment), but was not detected in the digests with other endonucleases, where the presence or absence of the 65-bp sequence is probably masked by its location (e.g., either in a large fragment or in the length-variable fragment described above). Side-by-side comparisons of double enzyme digests of mtDNAs with and without the 65-bp sequence revealed that, when present, it is located between adjacent $\mathrm{Nci}$ I and $E c o R$ V cleavage sites (see Fig. 3A, below). This also appears to parallel a type of variation (the 35-bp length difference) reported by Densmore et al. (1985) in the same region of $C$. tesselatus mtDNA. Some minor length variation and heteroplasmy were also evident in the $0.77-\mathrm{kb} M b o$ I fragment of the $C$. velox and Los Alamos County $C$. exsanguis mtDNAs.

The third type of length variation is the duplication of a $4.8-\mathrm{kb}$ portion of mtDNA that includes the control region and ribosomal-RNA genes. The evidence for and characterization of this unusual type of mtDNA variation has been presented elsewhere (Moritz and Brown, 1986, 1987). The 

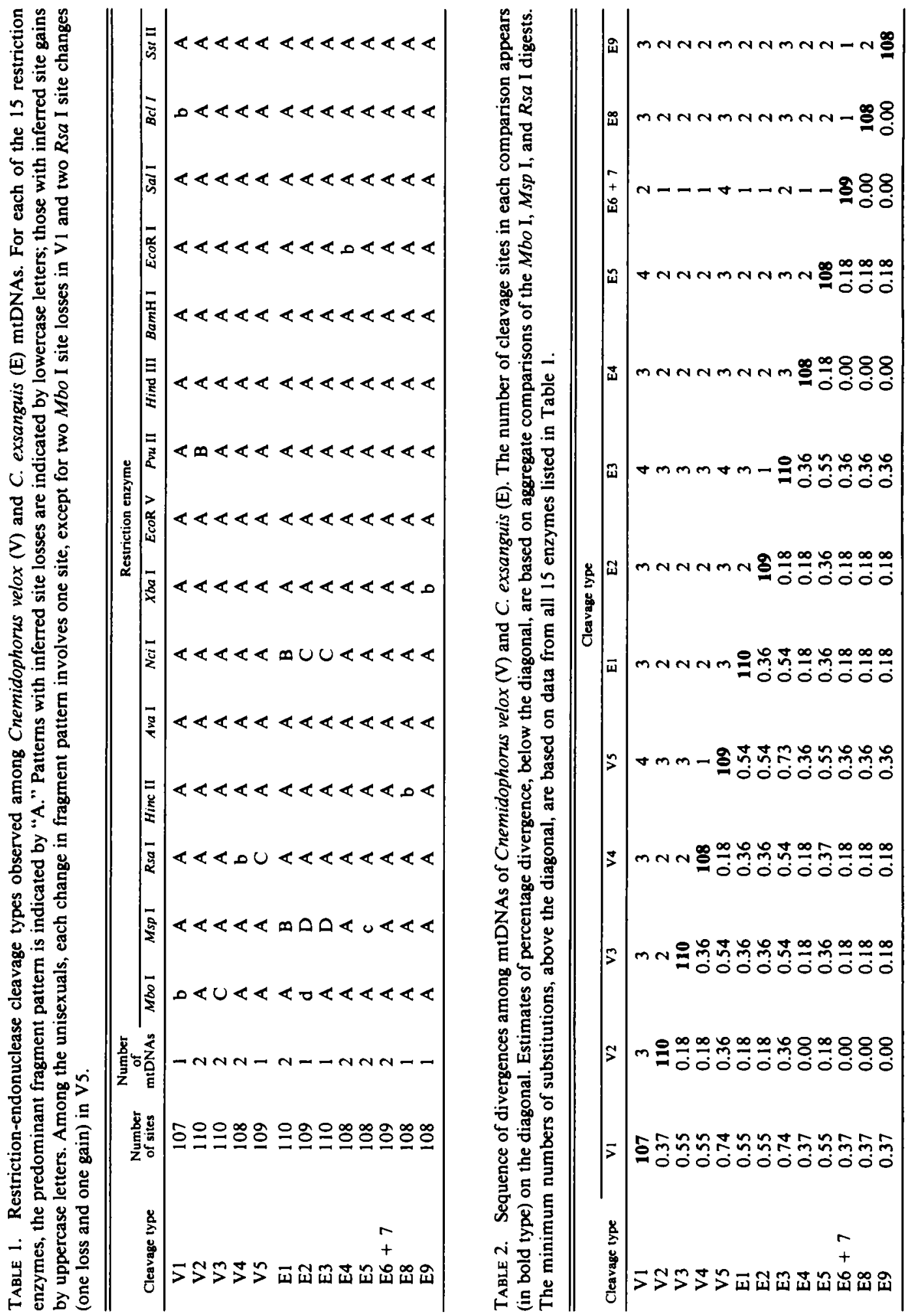


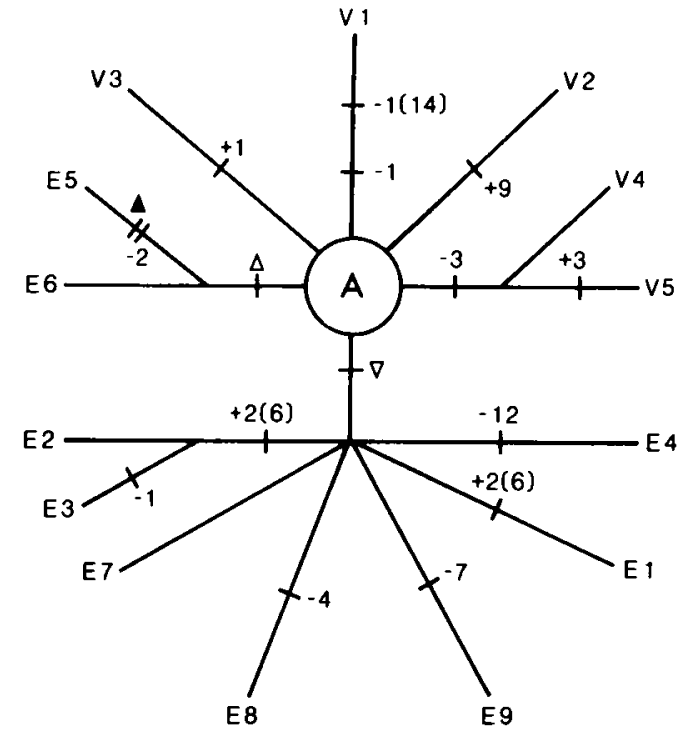

Fig. 2. Minimum-length network of mtDNAs from Cnemidophorus velox (V) and $C$. exsanguis (E). The circled $A$ represents a hypothetical ancestor (see text). The numbers on each branch refer to site losses or gains for the enzymes listed in Table 1. The samples are designated by species ( $V$ or $E$ ) and mtDNA cleavage type (Table 1). Symbols: $\Delta=4.8-k b$ duplication; $\Delta=$ 150-bp deletion; $\nabla=65$-bp length difference.

4.8-kb duplication occurred in the E6 and E7 C. exsanguis mtDNAs, and one of the duplicated segments in E7 has been modified further by a 150-bp deletion (Moritz and Brown, 1986).

Except for variation stemming from differences in copy number of short tandem repeats (which is probably generated rapidly and repeatedly; see Densmore et al., 1985), both length variation and cleavage-site changes can be used to infer relationships among the $C$. velox and $C$. exsanguis mtDNAs. To do so, an ancestral mtDNA that had the predominant cleavage-site profile for each enzyme ( $A$ in Table 1 ) was hypothesized. In obtaining the minimumlength network (Fig. 2), all deviations from this hypothetical mtDNA were treated as derived states. The representation of the 65 bp sequence as an insertion rather than as a deletion is arbitrary. The duplication is treated as a derived state because it is absent from the bisexual relatives of $C$. exsanguis and because large mtDNA duplications appear to be short-lived on an evolutionary time scale (Moritz and Brown, 1987; Moritz et al., 1987). Most of the cleavage-site changes are unique to samples from a single lizard or a single population (Fig. 2). However, C. velox mtDNAs V4 and V5 (from Los Alamos Co. and central Oregon) share the loss of an $R s a$ I site. The 65-bp insertion unites all $C$. exsanguis mtDNAs except E6 and $\mathrm{E} 7$, which share the 4.8-kb duplication. Most importantly, there are no consistent differences between the mtDNAs of $C$. velox and $C$. exsanguis.

\section{Mitochondrial-DNA Cleavage-Site Comparisons}

The absence of consistent differences between the mtDNAs of $C$. velox and $C$. exsanguis suggests that they were derived, on the maternal side, from the same bisexual species. This observation, in conjunction with previous analyses (Neaves, 1969) narrows the possible maternal ancestors to $C$. inornatus, $C$. costatus barrancorum, $C$. burti stictogrammus, and $C$. septemvittatus. Furthermore, $C$. septemvittatus is no longer a candidate, because its diagnostic morphological and allozymic characteristics are lacking in C. velox (Good and Wright, 1984; Dessauer and Cole, 1989; J. Wright and M. Simovich, unpubl.). Despite this, populations of $C$. septemvittatus from the Big Bend region of Texas (C. s. septemvittatus) and Chihuahua, Mexico, (C. s. scalaris) were included along with these other species and another northern subspecies of $C$. costatus (C. c. griseocephalus) in the cleavage-site comparisons.

A map of 30 cleavage sites in the mtDNA of $C$. velox and $C$. exsanguis (excluding rare variants) was constructed (Fig. 3A). This map was aligned with those for $C$. inornatus (Densmore et al., 1989a) and C. tesselatus (Densmore et al., 1985) using several conserved cleavage sites (circled in Fig. 3A). The locations of additional sites in the mtDNAs of the other bisexual species were inferred from changes in single-endonuclease digestion patterns in relation to these maps. Any cleavage site inferred to be within $400 \mathrm{bp}$ of a site for the same endonuclease in the mtDNA of another species was precisely mapped by comparing appropriate double digests in adjacent lanes of the same electrophoretic gel.

Altogether, 85 cleavage sites were mapped 
A

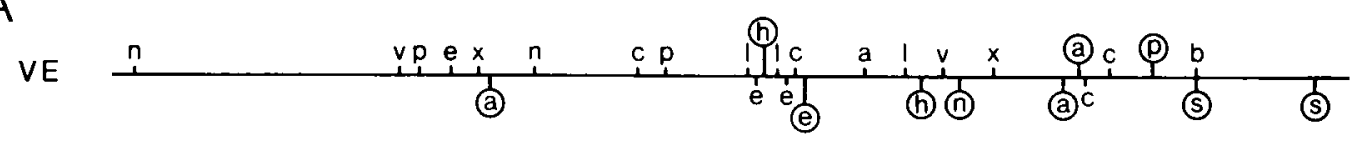

\begin{tabular}{|c|c|c|c|c|c|c|c|c|}
\hline VE & $\stackrel{n}{\perp}$ & $y$ & $\stackrel{x}{x}$ & $\stackrel{n}{1}$ & c & 11 & $v \quad x$ & c \\
\hline $\mathrm{CCb}$ & $\stackrel{n}{\perp}$ & Y & $\stackrel{x}{x}$ & & & 11 & 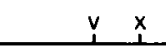 & c \\
\hline CBs & $\stackrel{n}{\longrightarrow}$ & v & $\stackrel{x}{\perp}$ & $\stackrel{n}{1}$ & & 11 & $\stackrel{x}{1}$ & c \\
\hline $\mathrm{CCg}$ & $\stackrel{n}{n} \quad \mathrm{e}$ & $\stackrel{?}{i}$ & & $n$ & & I! & $?$ & c \\
\hline $\mathrm{CSe}$ & & $\underset{T}{v}$ & & n & $c$ & 11 & $x$ & \\
\hline $\mathrm{CSc}$ & & a & & $\stackrel{n}{1}$ & c & $\begin{array}{l}\mathrm{nh} \\
1 \\
\end{array}$ & $\begin{array}{r}n \\
\times \quad n v \\
\end{array}$ & c \\
\hline CI & n e & a & & & & $\begin{array}{cc} & \mathrm{nh} \\
\mathrm{n} & \mathrm{x} \\
\end{array}$ & $x n$ & c \\
\hline 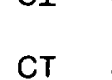 & $\stackrel{n}{1}$ & $\underline{\Sigma}$ & & n & & $\begin{array}{ll} & \mathrm{h} \\
\mathrm{n} & \mathrm{x} \\
\end{array}$ & $\begin{array}{r}\mathrm{n} \\
\times \quad n^{n} \\
\end{array}$ & \\
\hline $\begin{array}{l}\text { haracter } \\
\text { no. }\end{array}$ & 12 & 34 & 5 & 6 & 7 & 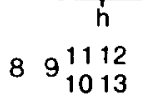 & $\begin{array}{rr}n & h \\
15_{16}^{17} & 19 \\
14^{18} & 20\end{array}$ & 21 \\
\hline
\end{tabular}

Fig. 3. Comparison of cleavage sites in mtDNAs of unisexual and bisexual Cnemidophorus. A) Cleavage map for $C$. velox and $C$. exsanguis; conserved sites are circled. B) Locations of phylogenetically informative sites in mtDNAs from $C$. velox and $C$. exsanguis and their bisexual relatives. Informative sites are numbered at the bottom. Species abbreviations: $\mathrm{VE}=C$. velox and $C$. exsanguis; $\mathrm{CCb}=C$. costatus barranocorum; $\mathrm{CBs}$ $=C$. burti stictogrammus; $\mathrm{CCg}=C$. costatus griseocephalus; $C S e=C$. septemvittatus septemvittatus; $\mathrm{CSc}=C$. s. scalaris; $\mathrm{CI}=C$. inornatus; $\mathrm{CT}=C$. tesselatus. Enzyme abbreviations: $\mathrm{a}=A v a \mathrm{I} ; \mathrm{b}=B a m \mathrm{H} \mathrm{I} ; \mathrm{c}=B c l \mathrm{I} ; \mathrm{e}$ $=E c o \mathrm{R} \mathrm{I} ; \mathrm{h}=H$ ind III; $\mathrm{l}=S a l \mathrm{I} ; \mathrm{n}=N c i \mathrm{I} ; \mathrm{p}=P v u \mathrm{II} ; \mathrm{S}=S s t \mathrm{II} ; \mathrm{v}=E c o \mathrm{R}$ V; $\mathbf{x}=X b a \mathrm{I}$.

among mtDNAs from eight taxa. When all sites are compared, the estimates of sequence divergence vary from $1.4 \%$ (between C. velox or C. exsanguis mtDNA and that of C. burti stictogrammus) to $12 \%$ (between the mtDNAs of C. tesselatus and C. s. scalaris) (Table 3). The larger divergences in Table 3 are probably underestimates due to convergent changes and reversals within cleavage sites (Upholt, 1977; Templeton, 1983). The UPGMA dendrogram of these divergence data (Fig. 4A) clearly excludes C. inornatus and both subspecies of $C$. septemvittatus as the maternal parent(s) of $C$. velox and C. exsanguis. However, three taxa (C. c. barrancorum, C. b. stictogrammus, and $C$. c. griseocephalus) remain as possibilities. Notably, the estimated levels of sequence difference between the mtDNA of C. velox or $C$. exsanguis and those of $C$. $c$. barrancorum (1.5\%) and C. b. stictogrammus $(1.4 \%)$ are virtually identical.
The origin of the C. velox/C. exsanguis mtDNA can also be assessed by treating the cleavage sites as characters and by confining the analysis to the 21 cleavage sites that had states (presence/absence) shared by two or more mtDNAs (Fig. 3B). The trees produced by parsimony analysis were rooted using $C$. tesselatus as the outgroup. C. tesselatus mtDNA is derived from its maternal parent, $C$. tigris marmoratus, a member of the tigris species group (Lowe et al., 1970). This group is a sister group to the sexlineatus group (Brown and Wright, 1979; Densmore et al., 1985, 1989b). Three most-parsimonious trees were generated by the exhaustive branch-and-bound search option of PAUP (Wagner parsimony), each with 32 steps and a consistency index of 0.66 . The consensus tree (Fig. 4B) indicates that the mtDNAs of C. c. barrancorum, $C$. b. stictogrammus, and C. velox/C. exsanguis form a trichotomy and are united by a de- 

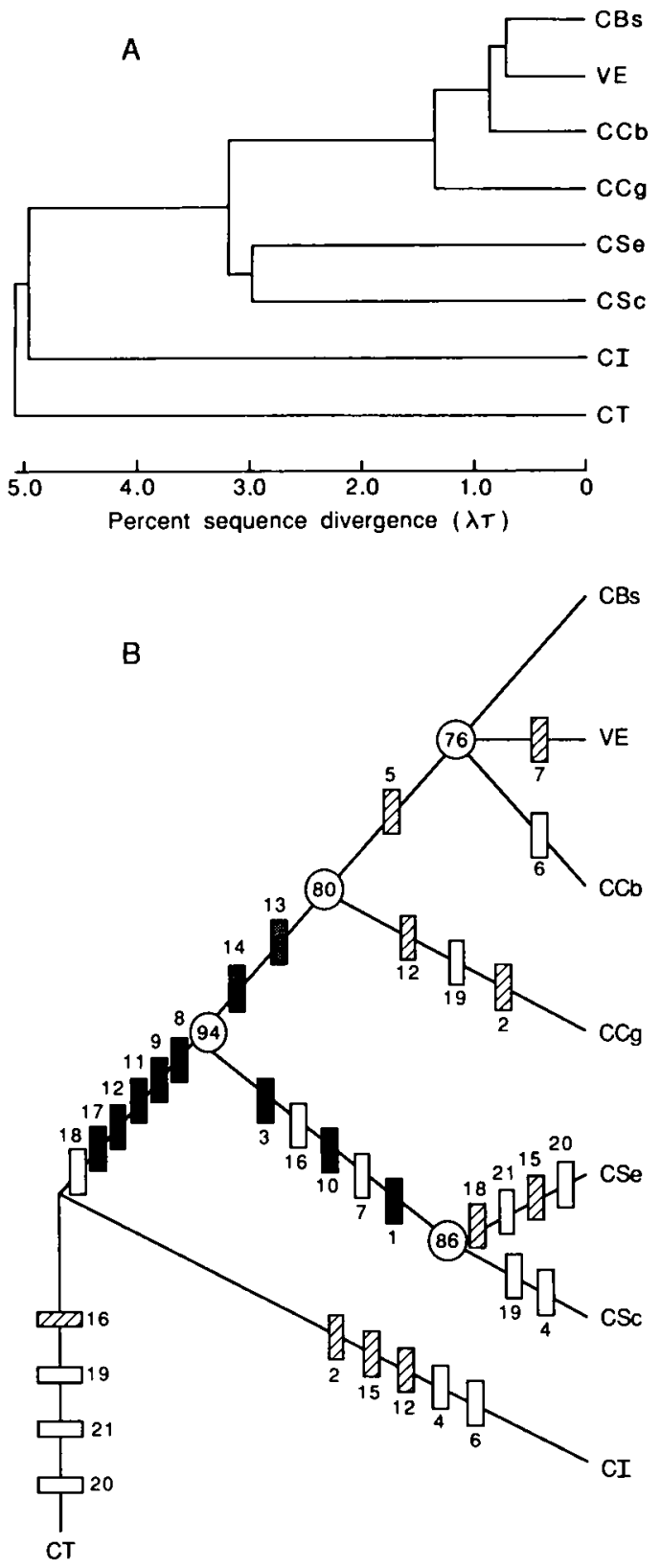

FIG. 4. Analyses of relationships among mtDNAs from Cnemidophorus exsanguis, $C$. velox, $C$. costatus, $C$. burti, and $C$. inornatus. Taxa are abbreviated as in Table 3. A) UPGMA dendrogram of sequence-divergence estimates from Table 3. B) Cladogram generated by phylogenetic analysis of cleavage sites, numbered as in Figure 3. The tree was rooted using C. tesselatus as an outgroup. Inferred character state changes are indicated on each branch: $=$ unique site gain; $\mathbb{D}=$ unique site loss; $\theta=$ convergent site gain; $\square=$ convergent site loss. Numbers at the interior nodes are the percentages of bootstrap replicates in which the taxa above and to the right were monophyletic. Species ab- rived $X b a$ I site. Thus, C. $c$. barrancorum and $C$. b. stictogrammus appear to be equally plausible as maternal ancestors of the two unisexuals.

The next longest tree produced by the Wagner parsimony analysis (33 steps, consistency index $=0.64$ ) included $C . c$. griseocephalus as a possible maternal ancestor. At 34 steps (consistency index $=0.62$ ), only $C$. inornatus is excluded from the polytomy with the $C$. velox/C. exsanguis mtDNAs. The stability of the cladogram was evaluated by bootstrapping characters with replacement over 100 replicates (Felsenstein, 1985). The trichotomy of $C$. velox/C. exsanguis, C. c. barrancorum, and C.b. stictogrammus was present in $76 \%$ of the replicates. The nodes excluding C. c. griseocephalus and the $C$. septemvittatus subspecies were maintained in $80 \%$ and $94 \%$ of the trees, respectively (Fig. 4B).

DeBry and Slade (1985) suggest the use of Dollo parsimony to maximize convergence of site losses over site gains. The shortest trees produced using Dollo parsimony were the same as those in the Wagner parsimony analysis (Fig. 4B).

\section{Discussion \\ Maternal Ancestry of C. velox and $\mathrm{C}$. exsanguis}

The mtDNA cleavage-site comparisons unambiguously exclude $C$. inornatus from consideration as the maternal ancestor of $C$. velox and $C$. exsanguis. These analyses also indicate that neither C.c. griseocephalus nor C. septemvittatus is the most probable maternal ancestor. Moreover, allozyme analyses exclude $C$. septemvittatus as a participant in the origin of $C$. velox (Dessauer and Cole, 1989; J. Wright and M. Simovich, unpubl.). Based on available data, the mtDNA of the unisexuals was most probably derived from either C. c. barrancorum or C. b. stictogrammus. Side-by-side comparisons of digests with endonucleases that cleave at

\footnotetext{
breviations: $\mathrm{CBs}=C$. burti stictogrammus $\mathrm{VE}=C$. velox and $C$. exsanguis; $\mathrm{CCb}=C$. costatus barrancorum; $\mathrm{CCg}=C$. c. griseocephalus; $\mathrm{CSe}=C$. septemvittatus septemvittatus; $\mathrm{CSc}=C$. s. scalaris; $\mathrm{CI}=C$. inornatus; $\mathrm{CT}=C$. tesselatus.
} 
TABlE 3. Percentage sequence divergences among the mtDNAs of Cnemidophorus velox or $C$. exsanguis and their bisexual relatives. The number of cleavage sites in each comparison appears (in bold type) on the diagonal. The divergence estimates appear below the diagonal, and their standard errors are given above it; estimates with standard errors $\geq 1 \%$ have been rounded to whole numbers.

\begin{tabular}{lrrrrrrrr}
\hline \multicolumn{1}{c}{ Taxon } & \multicolumn{9}{c}{ Taxon } \\
\cline { 2 - 9 } & CT & CI & CSe & CSc & CC8 & CCb & CBs & VE \\
\hline C. tesselatus (CT) & 37 & 2.3 & 2.0 & 2.3 & 2.3 & 2.4 & 2.3 & 2.3 \\
C. inornatus (CI) & 12 & 39 & 1.9 & 2.2 & 2.1 & 2.1 & 2.1 & 2.0 \\
C. septemvittatus septemvittatus (CSe) & 9 & 10 & $\mathbf{4 0}$ & 1.4 & 1.5 & 1.6 & 1.5 & 1.3 \\
C. s. scalaris (CSc) & 12 & 11 & 5 & 39 & 1.5 & 1.7 & 1.5 & 1.5 \\
C. costatus griseocephalus (CCg) & 10 & 9 & 6 & 6 & 26 & 1.0 & 0.9 & 0.8 \\
C. c. barrancorum (CCb) & 11 & 9 & 6 & 7 & 2.4 & 27 & 0.9 & 0.7 \\
C. burti stictogrammus (CBs) & 11 & 9 & 6 & 6 & 2.2 & 1.8 & 31 & 0.7 \\
C. velox and C. exsanguis (VE) & 11 & 9 & 5 & 6 & 1.9 & 1.5 & 1.4 & 30 \\
\hline
\end{tabular}

4-bp sites produced slightly higher mtDNA divergence estimates, possibly due to confounding effects of length variation, but did not help to resolve the maternal ancestry of the unisexuals. The strong similarity of both C. c. barrancorum and C. b. stictogrammus allozymes to one of the sets of alleles present in C. exsanguis was also noted by Good and Wright (1984) and by Dessauer and Cole (1989).

The divergence of $C$. velox and C. exsanguis mtDNAs from those of their putative maternal parents is greater than that observed in similar comparisons among other Cnemidophorus (e.g., Densmore et al., $1989 a, 1989 b$ ). The failure to identify a bisexual species whose mtDNA is less divergent from those of $C$. velox and $C$. exsanguis could be due to 1) insufficient sampling (either of other taxa or of geographic variation in the mtDNAs of $C$. c. barrancorum or C. b. stictogrammus), 2) extinction of the specific bisexual population(s) that were involved in the primary hybridization event(s) (see Good and Wright, 1984), or 3) changes accumulated subsequent to lineage separation. That accumulated changes could be a significant factor is indicated by the fact that there is more variation among the mtDNAs of $C$. velox and $C$. exsanguis than among other unisexual Cnemidophorus. The most divergent mtDNAs of $C$. velox and $C$. exsanguis differ by about $0.7 \%$, which is half of the difference between their mtDNAs and those of C. b. stictogrammus and C. c. barrancorum. Regardless, the level of genetic differentiation between the unisexuals and each of the bisexuals is well within the range observed among conspecific populations of other vertebrates (reviewed in Avise and Lansman [1983] and in Avise [1986]), including those of bisexual Cnemidophorus (Densmore et al., 1989a, 1989b; C. Moritz, J. Wright, and W. Brown, unpubl.).

\section{The Origins and Ages of $\mathrm{C}$. velox} and $\mathrm{C}$. exsanguis

The quality of the evidence for the evolution of parthenogenesis via hybridization varies among the unisexual species of Cnemidophorus (reviewed by Cole [1975, 1985], Wright [1978] Darevsky et al. [1985], Walker [1986], Cole et al. [1988], and Dessauer and Cole [1989]). There are several triploid unisexual taxa in which two of the three haploid genomes are from the same bisexual species and for which no diploid hybrid intermediate is known. Cnemidophorus velox is one such lineage; allozyme analyses of this species indicate that two of its three sets of genes are derived from C. inornatus (Neaves, 1969; Dessauer and Cole, 1989; J. Wright and $M$. Simovich, unpubl.). In such cases, it has been postulated that parthenogenesis could have arisen spontaneously in a female belonging to a diploid bisexual species and that subsequent hybridization of this female with a male of another species could have resulted in the formation of triploid hybrid progeny (Darevsky et al., 1985; see also Cuellar, 1974 fig. 1). The possibility that an unreduced diploid oocyte produced by a $C$. inornatus female (whether bisexual or "spontaneously parthenogenetic") was involved in the formation of $C$. velox is excluded by the mtDNA comparisons, since 
in such a case $C$. velox would have mtDNA derived from $C$. inornatus. The first event in the formation of $C$. velox must, therefore, have been the founding of a hybrid diploid (and presumably parthenogenetic) lineage by hybridization between a female of either C. c. barrancorum or C. b. stictogrammus and a male $C$. inornatus. Subsequently, a member of this unknown (and probably extinct) lineage must have backcrossed with a C. inornatus male to produce the first triploid $C$. velox.

The absence of any consistent differences between the mtDNAs of $C$. velox and $C$. exsanguis suggests that both are derived from the same bisexual species on the maternal side. Additional support for a partly shared ancestry between $C$. velox and $C$. exsanguis is provided by comparisons at variable allozyme loci (Dessauer and Cole, 1989; J. Wright and M. Simovich, unpubl.). Hence, the divergent morphological and allozyme features of the two species must have arisen largely as a consequence of hybridization between two (or more) of the ancestral allodiploid females and males of either $C$. inornatus (to produce $C$. velox [Neaves, 1969; Dessauer and Cole, 1989; J. Wright and M. Simovich, unpubl.]) or $C$. septemvittatus (to produce $C$. exsanguis [Good and Wright, 1984; Dessauer and Cole, 1989]).

The variation among the $C$. velox and $C$. exsanguis mtDNAs, although low, is greater than that among mtDNAs from $C$. tesselatus (Densmore et al., 1985, 1989b). If all of the differences among the $C$. velox and C. exsanguis mtDNAs are due to accumulated mut itions, then these lineages could be older than those constituting the parthenogenetic species $C$. tesselatus. However, this conclusion relies on an assumption of equal rates of change, which may be unreasonable at such low divergence levels due to chance effects alone. It is also possible that some of the mtDNA variation stems from multiple hybridization events involving different females of either C. c. barrancorrum or $C$. b. stictogrammus. This hypothesis can only be tested through more detailed comparisons of mitochondrial and nuclear gene variation in the bisexual and unisexual populations. In any case, the absolute level of mtDNA differentiation among
C. velox and C. exsanguis is among the lowest reported for natural populations (e.g., compare with humans [Brown, 1980] or Atlantic eels [Avise et al., 1986]; reviewed by Avise [1986]), so that the formation of these parthenogenetic species must be regarded as a relatively recent event.

\section{ACKNOWLEDGMENTS}

We thank G. Bradley, R. Bowker, D. Good, J. Karges, C. Lieb, C. Lowe, R. Martori, M. Rand, M. Ruggles, J. Salmon, and $\mathrm{K}$. Wright for specimens and field assistance; K. Blakely and L. Densmore for laboratory assistance; D. Crews, C. J. Cole, L. Densmore, T. Dowling, J. Easley, and F. Kraus for manuscript reviews; and D. Bay and M. Van Bolt for assistance with the illustrations. This research was supported in part by grants from the National Science Foundation and the National Institutes of Health, by Rackham, Phoenix, and Biomedical Research grants from the University of Michigan, and by the Natural History Museum of Los Angeles County Foundation.

\section{LITERATURE CITED}

Avise, J. C. 1986. Mitochondrial DNA and the evolutionary genetics of higher animals. Phil. Trans. Roy. Soc. Lond. B 312:325-342.

Avise, J. C., G. S. Helfman, N. C. Saunders, and L. S. Hales. 1986. Mitochondrial DNA differentiation in North Atlantic eels: Population genetic consequences of an unusual life history pattern. Proc. Nat. Acad. Sci. USA 83:4350-4354.

Avise, J. C., AND R. A. Lansman. 1983. Polymorphism of mitochondrial DNA in populations of higher animals, pp. 147-164. In M. Nei and R. K. Koehn (eds.), Evolution of Genes and Proteins. Sinauer, Sunderland, MA.

Brown, W. M. 1980. Polymorphism in mitochondrial DNA of humans as revealed by restriction endonuclease analysis. Proc. Nat. Acad. Sci. USA 77:3605-3609.

Brown, W. M., AND J. W. Wright. 1979. Mitochondrial DNA analyses and the origin and relative age of parthenogenetic lizards (genus Cnemidophorus). Science 203:1247-1249.

COLE, C. J. 1975. Evolution of parthenogenetic species of reptiles, pp. 340-355. In R. Reinboth (ed.), Intersexuality in the Animal Kingdom. Springer-Verlag, Berlin, W. Ger.

- 1985. Taxonomy of parthenogenetic species of hybrid origin. Syst. Zool. 34:359-363.

Cole, C. J., H. C. Dessauer, and G. F. Barrowclough. 1988. Hybrid origin of a unisexual species of whiptail lizard, C. neomexicanus, in western North 
America: New evidence and a review. Amer. Mus. Novit. 2905:1-38.

CUELLAR, O. 1974. On the origin of parthenogenesis in vertebrates: The cytogenetic factors. Amer. Natur. 108:625-648.

DAREVSKY, I. S., L. A. KupriYanova, AND T. UzzeLl. 1985. Parthenogenesis in reptiles, pp. 413-526. In C. Gans (ed.), Biology of the Reptilia, Vol. 15B. Wiley, Chichester, U.K.

DeBry, R. W., and N. A. Slade. 1985. Cladistic analysis of restriction endonuclease cleavage maps within a maximum-likelihood framework. Syst. Zool. 34:21-35.

Dessauer, H. C., and C. J. Cole. 1989. Diversity between and within nominal forms of unisexual lizards, pp. 49-71. In R. M. Dawley and J. P. Bogart (eds.), Evolution and Ecology of Unisexual Vertebrates. New York State Museum, Albany.

Densmore, L. D., C. Moritz, J. W. Wright, and W. M. BROWN. 1989a. Mitochondrial-DNA analyses and the origin and relative age of parthenogenetic lizards (genus Cnemidophorus). IV. Nine sexlineatus group unisexuals. Evolution 43:969-983.

DenSmore, L. D., J. W. Wright, AND W. M. BRoWN. 1985. Length variation and heteroplasmy are frequent in mitochondrial DNA from parthenogenetic and bisexual lizards (genus Cnemidophorus). Genetics 110:689-707.

- 1989b. Mitochondrial DNA analyses and the origin and relative age of parthenogenetic lizards (genus Cnemidophorus). II. C. neomexicanus and the $C$. tesselatus complex. Evolution 43:943-957.

Felsenstein, J. 1985. Confidence limits on phylogenies: An approach using the bootstrap. Evolution 39:783-792.

Good, D. A., AND J. W. Wright. 1984. Allozymes and the hybrid origin of the parthenogenetic lizard Cnemidophorus exsanguis. Experientia 40:10121014.

Lowe, C. H., J. W. WRight, C. J. COle, AND R. L. BEZY. 1970. Chromosomes and evolution of the species groups of Cnemidophorus (Reptilia: Teiidae). Syst. Zool. 19:128-141.

Masin, T. P., AND D. M. SeCoy. 1986. A checklist of the lizard genus Cnemidophorus (Teiidae). Contr. Zool. Univ. Colorado Mus. 1:1-60.

MORITZ, C., AND W. M. Brown. 1986. Tandem duplication of D-loop and ribosomal RNA sequences in lizard mitochondrial DNA. Science 233:14251427.
- 1987. Tandem duplications in animal mitochondrial DNAs: Variation in incidence and gene content among lizards. Proc. Nat. Acad. Sci. USA 84:7183-7187.

Moritz, C., W. M. Brown, L. D. Densmore, J. W. Wright, D. Vyas, S. Donnellan, M. Adams, and P. BAVERSTOCK. 1989. Genetic diversity and the dynamics of hybrid parthenogenesis in Cnemidophorus (Teiidae) and Heteronotia (Gekkonidae), pp. 87-112. In R. M. Dawley and J. P. Bogart (eds.), Evolution and Ecology of Unisexual Vertebrates. New York State Museum, Albany.

Moritz, C., T. E. Dowling, AND W. M. Brown. 1987. Evolution of animal mitochondrial DNA: Relevance for population biology and systematics. Ann. Rev. Ecol. Syst. 18:269-292.

NeAves, W. B. 1969. Adenosine deaminase phenotypes among sexual and parthenogenetic lizards in the genus Cnemidophorus (Teiidae). J. Exp. Zool. 171:175-184.

Nei, M., J. C. Stephens, and N. SaItou. 1985. Methods for computing the standard errors of branching points in an evolutionary tree and their application to molecular data from humans and apes. Molec. Biol. Evol. 2:66-85.

NeI, M., aND F. TAIIMA. 1983. Maximum likelihood estimation of the number of nucleotide substitutions from restriction site data. Genetics 105:207217.

SNEATH, P. H. A., AND R. R. Sokal. 1973. Numerical Taxonomy. Freeman, San Francisco, CA.

Templeton, A. R. 1983. Convergent evolution and nonparametric inferences from restriction data and DNA sequences, pp. 151-179. In B. S. Weir (ed.), Statistical Analysis of DNA Sequence Data. Dekker, N.Y.

UPHOLT, W. B. 1977. Estimation of DNA sequence divergence from comparison of restriction endonuclease digests. Nucl. Acids Res. 4:1257-1265.

WALKER, J. M. 1986. The taxonomy of parthenogenetic species of hybrid origin: Cloned hybrid populations of Cnemidophorus (Sauria: Teiidae). Syst. Zool. 35:427-440.

WRIGHT, J. W. 1978. Parthenogenetic lizards. Science 202:1152-1154.

Corresponding Editor: C. F. Aquadro 


\section{APPENDIX}

All Cnemidophorus used in these analyses have been deposited as voucher specimens in the herpetological collection of the Natural History Museum of Los Angeles County (LACM). Abbreviated locality data and LACM catalog numbers are presented in the table below, except those for $C$. inornatus, which are given in an accompanying paper (Densmore et al., 1989a). More complete specimen data may be requested from J.W.W.

\begin{tabular}{lllc}
\hline \hline \multicolumn{1}{c}{ Taxon } & \multicolumn{1}{c}{ Collection locality } & $N$ & voucher specimens \\
\hline C. burti stictogrammus & Sonora, Mexico & 1 & 122411 \\
& Pima Co., AZ & 2 & $135444-135445$ \\
C. costatus barrancorum & Sonora, Mexico & 4 & $122409-122410,130369$, \\
& & & 134683 \\
C. costatus griseocephalus & Guerrero, Mexico & 2 & $130352-130353$ \\
C. septemvittatus septemvittatus & Presidio Co., TX & 2 & $128329-128330$ \\
& Coahuila, Mexico & 2 & 130627,130630 \\
C. septemvittatus scalaris & Chihuahua, Mexico & 1 & 122407 \\
& Aguascalientes, Mexico & 4 & $135880-135883$ \\
C. exsanguis & Cochise Co., AZ & 2 & 131760,134802 \\
& Greenlee Co., AZ & 3 & $137213-137215$ \\
& Catron Co., NM & 2 & $134288-134289$ \\
& Guadalupe Co., NM & 1 & 134299 \\
& Sandoval Co., NM & 3 & $137217,135934,135936$ \\
C. velox & Socorro Co., NM & 1 & 137216 \\
& Apache Co., AZ & 3 & $137208-137210$ \\
& Yavapai Co., AZ & 2 & $137206-137207$ \\
& Bernalillo Co., NM & 1 & 137211 \\
& Sandoval Co., NM & 2 & $135944-135945$ \\
& Socorro Co., NM & 2 & $134386-134387$ \\
& Jefferson Co., OR & 1 & 137212 \\
\hline
\end{tabular}

